\title{
Patterns of evolution of host proteins involved in retroviral pathogenesis Millan Ortiz ${ }^{1}$, Gabriela Bleiber ${ }^{1}$, Raquel Martinez ${ }^{1}$, Henrik Kaessmann*2 and Amalio Telenti*1
}

\author{
Address: ${ }^{1}$ Institute of Microbiology and University Hospital, University of Lausanne, Switzerland and ${ }^{2}$ Center for Integrative Genomics, University \\ of Lausanne, Lausanne, Switzerland \\ Email: Millan Ortiz - millan.Ortiz-serrano@chuv.ch; Gabriela Bleiber - Gabriela.x.bleiber@gsk.com; \\ Raquel Martinez - Raquel.martinez@chuv.ch; Henrik Kaessmann* - Henrik.Kaessmann@unil.ch; Amalio Telenti* - amalio.telenti@chuv.ch \\ * Corresponding authors
}

Published: 07 February 2006

Retrovirology2006, 3:1। doi:10.1186/1742-4690-3-II

This article is available from: http://www.retrovirology.com/content/3/I/I I

(c) 2006Ortiz et al; licensee BioMed Central Ltd.

This is an Open Access article distributed under the terms of the Creative Commons Attribution License (http://creativecommons.org/licenses/by/2.0), which permits unrestricted use, distribution, and reproduction in any medium, provided the original work is properly cited.
Received: 23 December 2005
Accepted: 07 February 2006

\begin{abstract}
Background: Evolutionary analysis may serve as a useful approach to identify and characterize host defense and viral proteins involved in genetic conflicts. We analyzed patterns of coding sequence evolution of genes with known (TRIM5 $\alpha$ and APOBEC3G) or suspected (TRIMI9/PML) roles in virus restriction, or in viral pathogenesis (PPIA, encoding Cyclophilin $A$ ), in the same set of human and non-human primate species.

Results and conclusion: This analysis revealed previously unidentified clusters of positively selected sites in APOBEC3G and TRIM5 $\alpha$ that may delineate new virus-interaction domains. In contrast, our evolutionary analyses suggest that PPIA is not under diversifying selection in primates, consistent with the interaction of Cyclophilin A being limited to the HIV-IM/SIVcpz lineage. The strong sequence conservation of the TRIM/9/PML sequences among primates suggests that this gene does not play a role in antiretroviral defense.
\end{abstract}

\section{Background}

Evolutionary genomics approaches have been proposed as powerful tools to identify protein regions relevant for host-pathogen interactions [1]. Identifying signatures of genetic conflict can open the way to biological testing of hypotheses regarding the function of host proteins. In retrovirology, the utility of this approach was recently demonstrated in evolutionary analyses of the antiretroviral defense genes TRIM5 $\alpha$, encoding a retrovirus restriction factor targeting the viral capsid $[2,3]$, and $A P O B E C 3 G$, coding for a cytidine deaminase that hypermutates viral DNA in primates [4-6]. Both genes were shown to have been shaped by positive selection, which led to the rapid fixation of adaptive amino acid replacement substitu- tions. The two genes revealed two different patterns of positive selection: a localized region of rapid change in TRIM5 $\alpha$ [3], and a pattern where positively selected residues are scattered throughout the sequence in APOBEC3G [5].

To assess the potential of an evolutionary approach to identify further primate genes/proteins involved in virus defense, we analyzed coding sequence evolution of two additional genes, TRIM19 (PML) and PPIA, and reassessed the selective signatures of TRIM $5 \alpha$ and APOBEC3G in a common set of primates, representing 40 million years of evolution [7]. TRIM19 (PML) was proposed to possess anti(retro)viral activity $[8,9]$, while Cyclophilin A, 


\section{$\operatorname{TRIM5\alpha }$}

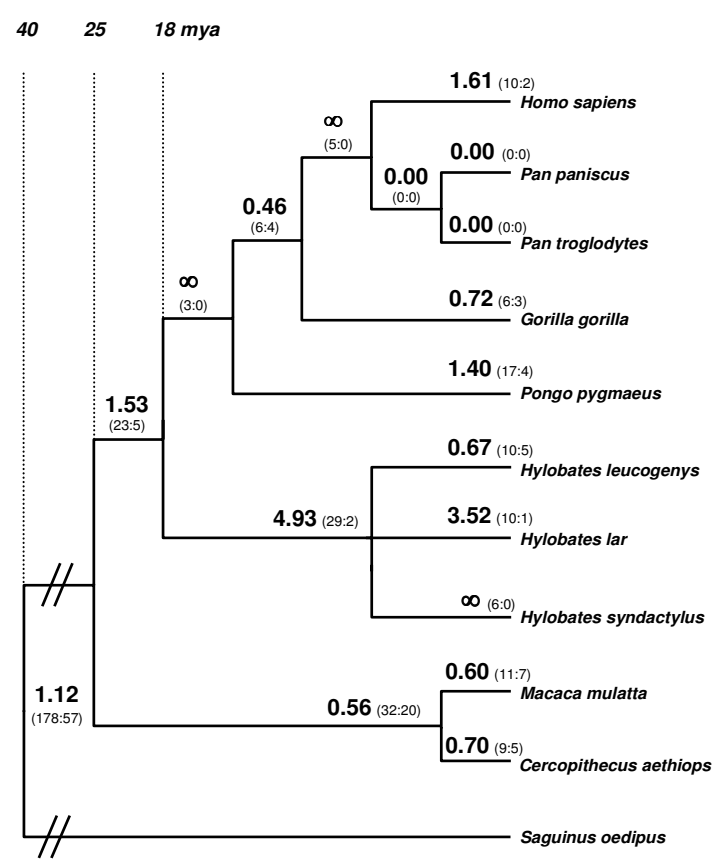

\section{TRIM19 (PML)}

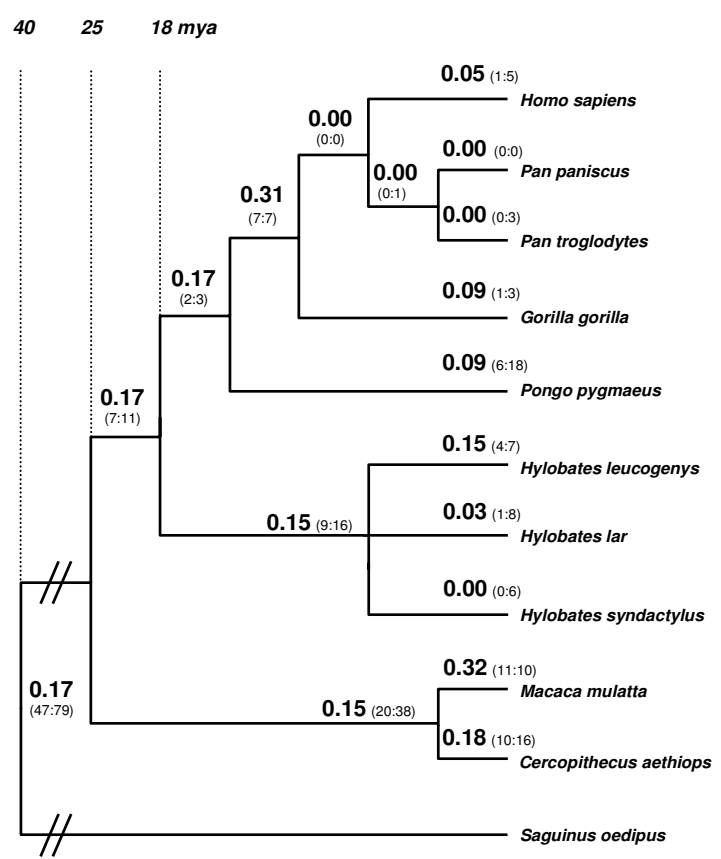

\section{APOBEC3G}

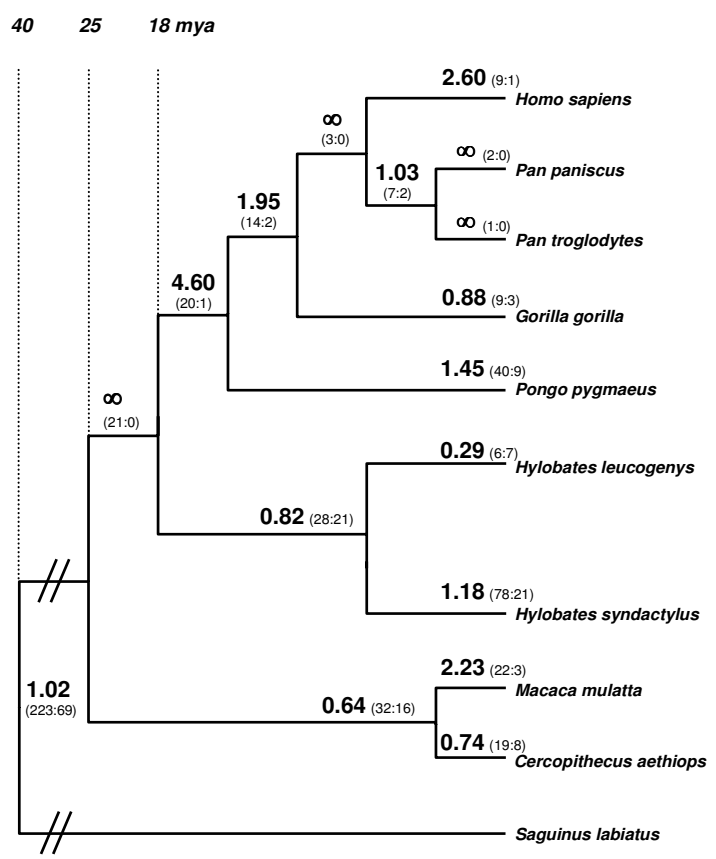

\section{PPIA (Cyclophilin A)}

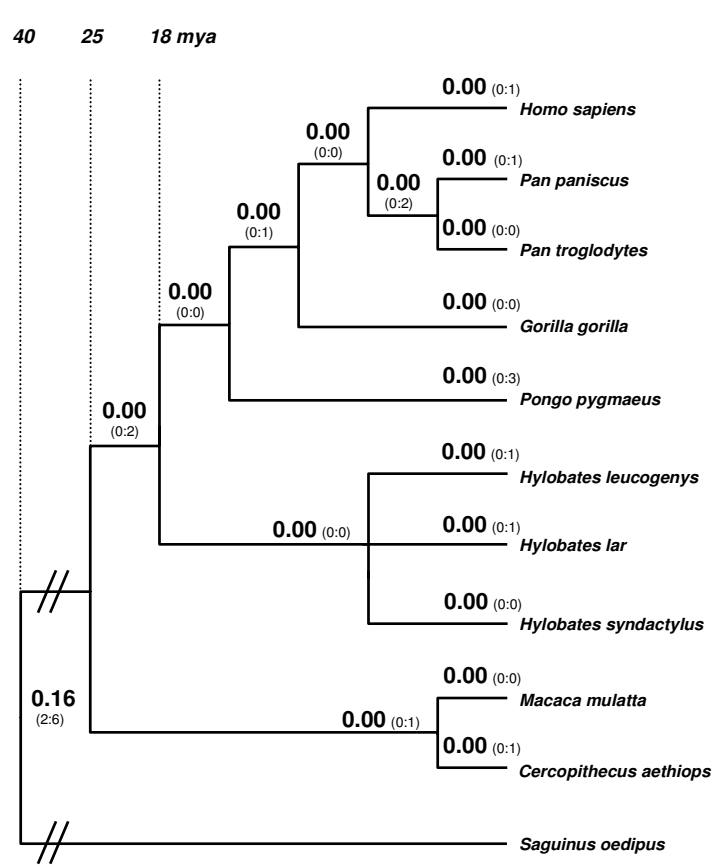

Figure I

Phylogenetic trees of candidate antiviral defense genes. $K_{A} / K_{S}$ values and the estimated number of nonsynonymous and synonymous substitutions (in parentheses) for each branch are indicated. Approximate divergence times in millions of years (mya) are shown [7]. 
Table I: Codeml analyses using site-specific models.

\begin{tabular}{|c|c|c|c|c|c|}
\hline \multicolumn{6}{|c|}{ TRIM5 $\alpha$} \\
\hline Site-specific Models ${ }^{a}$ & $\omega_{0}^{b}$ & $\omega_{1}{ }^{c}$ & $\omega_{2}{ }^{d}$ & LogL & Sites with $\omega>1$ e \\
\hline C: Mla & $0.00(34.91 \%)$ & 1.00 (65.09\%) & & -4117.12 & \\
\hline $\mathrm{D}: \mathrm{M} 2 \mathrm{a}$ & $0.00(26.04 \%)$ & 1.00 (61.67\%) & $6.37 *(12.29 \%)$ & -4087.97 & II sites \\
\hline \multicolumn{6}{|c|}{ APOBECЗG } \\
\hline Site-specific Models & $\omega_{0}$ & $\omega_{1}$ & $\omega_{2}$ & LogL & Sites with $\omega>1$ \\
\hline C: Mla & $0.03(37.56 \%)$ & 1.00 (62.44\%) & & $-4 \mid 87.55$ & \\
\hline $\mathrm{D}: \mathrm{M} 2 \mathrm{a}$ & $0.00(28.28 \%)$ & $1.00(48.60 \%)$ & $4.40 *(23.11 \%)$ & $-4 \mid 48.85$ & 24 sites \\
\hline \multicolumn{6}{|c|}{ TRIMI9 (PML) } \\
\hline $\begin{array}{c}\text { Site-specific Models } \\
\text { C: Mla }\end{array}$ & $\begin{array}{l}\omega_{0} \\
0.09 \text { (91.47\%) }\end{array}$ & $\begin{array}{l}\omega_{1} \\
1.00(8.53 \%)\end{array}$ & $\omega_{2}$ & $\begin{array}{l}\text { LogL } \\
-5215.40\end{array}$ & Sites with $\omega>1$ \\
\hline $\mathrm{D}: \mathrm{M} 2 \mathrm{a}$ & $0.11(97.25 \%)$ & $1.00(0.00 \%)$ & $2.5(2.75 \%)$ & -5214.46 & $n / a^{f}$ \\
\hline \multicolumn{6}{|c|}{ PPIA (Cyclophilin A) } \\
\hline Site-specific Models & $\omega_{0}$ & $\omega_{1}$ & $\omega_{2}$ & LogL & Sites with $\omega>1$ \\
\hline C: Mla & $0.05(100 \%)$ & $1.00(0 \%)$ & & -751.04 & \\
\hline $\mathrm{D}: \mathrm{M} 2 \mathrm{a}$ & $0.05(100 \%)$ & $1.00(0.00 \%)$ & $1.00(0.00 \%)$ & -751.04 & $n / a^{f}$ \\
\hline
\end{tabular}

\footnotetext{
a the likelihood models used are described in the text

$b$ class of sites under purifying selection

c class of sites evolving neutrally

${ }^{d}$ class of sites that may show $K_{A} / K_{S}>$ I

e sites pinpointed to be under positive selection by Bayes Empirical Bayes analysis

$f$ test not applicable (Mla and M2a not significantly different)
}

encoded by PPIA (peptidyl-prolyl cis-trans isomerase), is incorporated into HIV-1 particles through an interaction with the viral capsid [10]. Cyclophilin A is incorporated only into viral particles of viruses of the HIV- $1 \mathrm{M} / \mathrm{SIV}_{\mathrm{CPZ}}$ lineage, where it is required for viral replication [11].

To trace the evolutionary history of these genes, we first sequenced their coding regions from eleven primate species [see Additional files 1 and 2]. We then analyzed their substitutional patterns in the framework of the accepted primate phylogeny [7] using several codon-based maximum likelihood procedures as implemented in the codeml tool of the PAML program package [12] (Figure $1)$.

To obtain an overview of the coding sequence evolution, we estimated the number of nonsynonymous (KA) over synonymous (KS) substitutions per site (averaged over the entire sequence) for each branch of the trees using the free-ratio model of codeml [12]. Similarly to previous reports $[3,5,6]$, this analysis revealed generally high KA/KS values on the different branches of the TRIM $5 \alpha$ and APOBEC3G trees (average KA/KS 1.1 for both genes), indicating that these genes show accelerated amino acid replacement rates due to the action of positive selection [13]. In contrast, PPIA and TRIM19 (PML) show low KA/
KS values (0.05 and 0.15 , respectively, when averaged over the entire tree), suggesting that their protein sequences have been strongly preserved by purifying selection (Figure 1).

In more detailed analyses, we then utilized models that allow for different $K_{\mathrm{A}} / K_{\mathrm{S}}$ rates at different sites of the sequences, because adaptive evolution often occurs at a limited number of sites [14]. We first compared a null model ("M1a", $[15,16])$, which assumes two site classes (sites under purifying selection and neutrally evolving sites), to an alternative model ("M2a", [15,16]), which adds a third site class that allows for sites with $K_{\mathrm{A}} / K_{\mathrm{S}}>1$, using likelihood ratio tests [17]. This comparison revealed that the alternative model provides a significantly better fit $\left(P<10^{-30}\right)$ for the TRIM5 $\alpha$ and APOBEC3G genes than the null model, whereas the null model could not be rejected for TRIM19 and PPIA (Table 1 ). The $K_{\mathrm{A}} / K_{\mathrm{S}}$ for the additional site class is larger than 1 for both TRIM5 $\alpha\left(K_{\mathrm{A}}\right)$ $\left.K_{\mathrm{S}} \sim 6.4\right)$ and APOBEC3G $\left(K_{\mathrm{A}} / K_{\mathrm{S}} \sim 4.4\right)$, strongly suggesting adaptive protein evolution driven by positive selection at a subset of sites. Thus, this analysis supports the hypothesis that TRIM5 $\alpha$ and APOBEC3G evolved under positive selection. Contrary to this, nearly all sites of TRIM19 and PPIA ( $91.5 \%$ and $100 \%$, respectively) are under purifying selection (Table 1). 
A

TRIM5 alpha
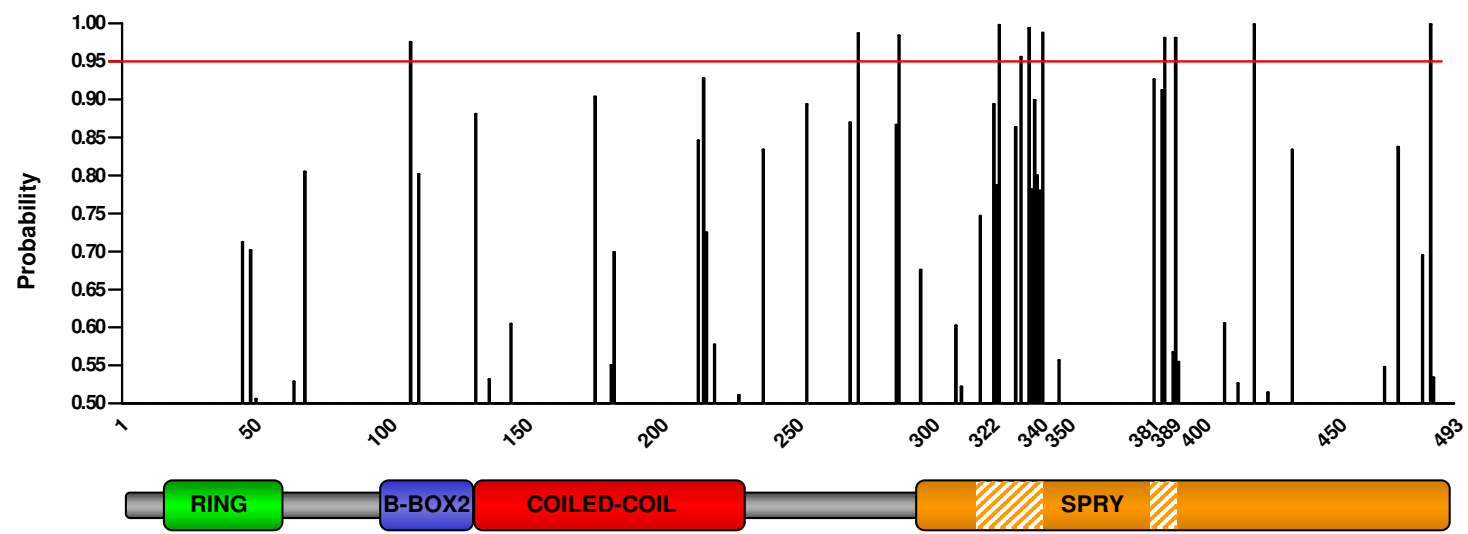

Protein domains

B APOBEC3G
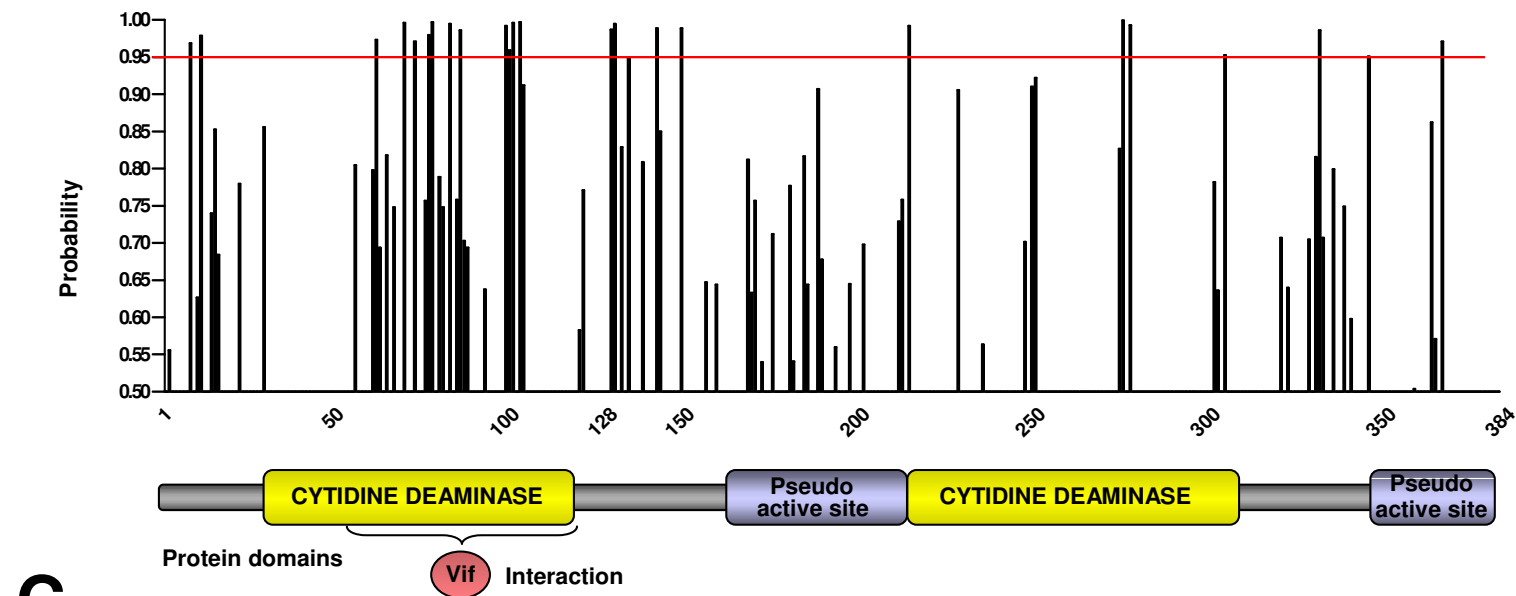

C

TRIM19 (PML)

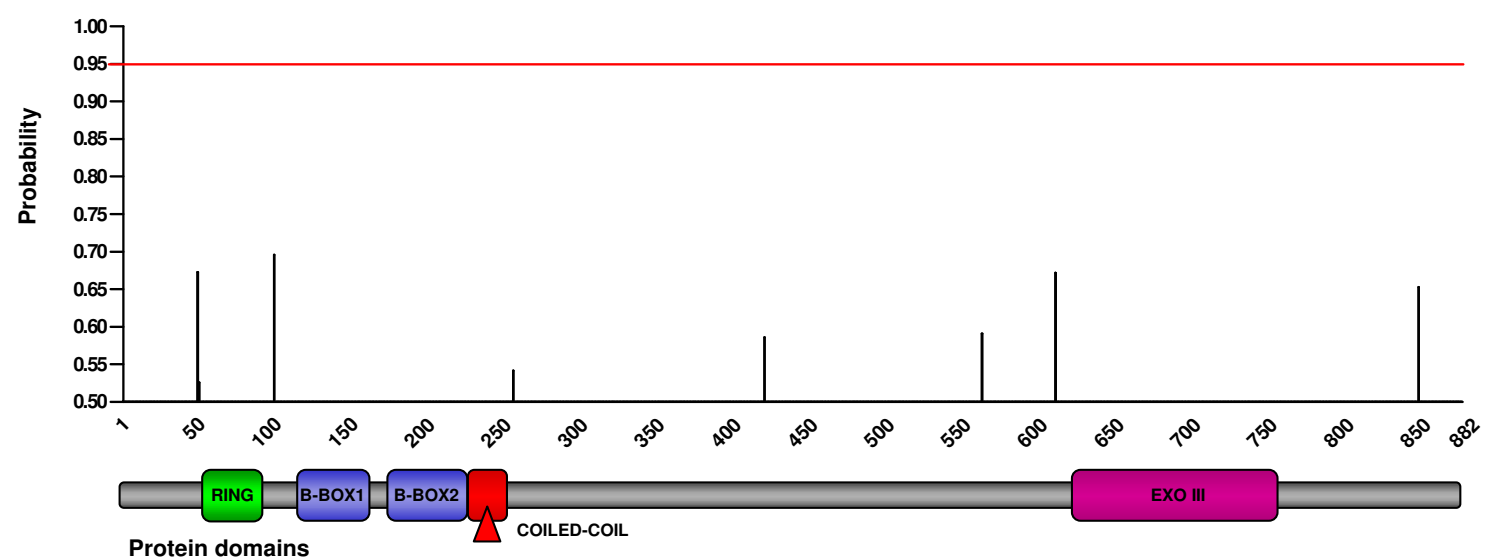

Figure 2

Codons under positive selection in TRIM5 $\alpha$ and APOBEC3G. Y-axis: Probabilities of positively selected codons (see text). X-axis: amino acid numbering and functional domains. TRIM/9 is shown for comparison. 
Using a recently developed Bayesian approach [16], we analyzed the site class under positive selection in TRIM5 $\alpha$ and APOBEC $3 G$ in more detail. For TRIM5 $\alpha, 11$ of 493 (2\%) codon sites can be predicted to be positively selected with high confidence ( $P>0.95$, Figure $2 \mathrm{~A})$. Two clusters of positive selection are found in the SPRY domain. The first cluster resides between amino acids 322 to 340 in the variable region 1 (v1, [18]), a region previously described as a "patch" of positive selection [3]. Replacement of the $\mathrm{v} 1$ region, or of specific amino acids within v1, modifies the restriction pattern of TRIM5 $\alpha[19,20]$. The second cluster, localized between amino acids 381 to 389, corresponds to the previously described variable region v2 of the SPRY domain [18]. Substitution of the human v2 region by a Rhesus monkey v2 exhibits no inhibitory activity against HIV-1 or a N-MLV $\mathrm{L}_{\mathrm{L} 17 \mathrm{H}}$ chimera $[19,20]$. However, the role of v2 in species-specific lentiviral restriction has not yet been extensively tested.

The analysis also predicts a large number ( 24 of $384,6 \%$ ) of positively selected sites in the APOBEC $3 G$ (Figure 2B) sequence. This result is consistent with previous reports by Sawyer et al. [5]. However, the inclusion of several new species from an additional hominoid lineage, Hylobatidae (gibbons and siamangs), points to the existence of a cluster of residues under positive selection between amino acids 62 and 103, the region that defines the Vifinteraction domain [21]. The protein Vif, which counteracts the activity of APOBEC3G, is encoded by nearly all lentiviruses [22]. Within the Vif-interaction domain of APOBEC3G, 10 residues can be pinpointed to have evolved under strong positive selection. Interestingly, the APOBEC3G amino acid position 128, which controls the ability of the HIV-1 Vif protein to bind and inactivate this host defense factor $[23,24]$, is correctly identified as being positively selected $(P>0.987)$.

The parallel assessment of multiple genes in the same set of primates allows for several considerations and conclusions. First, by including additional primate lineages, we modify and complement previously observed patterns for two antiviral defense genes/proteins. For TRIM $5 \alpha$, our analysis confirms previous results by Sawyer et al [3], but underscores the potential interest of the second variable region of the SPRY domain that may be of functional relevance and merits further experimental analysis. With respect to APOBEC3G, our analysis extends previous reports that showed protein-wide distribution of positively selected residues. It suggests that this protein potentially carries a functionally relevant cluster of selected residues that coincides with the region of HIV-1-Vif interaction $[23,24]$. Positive selected sites by Bayes Empirical Bayes Inference with probabilities $P>0.95$ for the two proteins are listed in Additional file 3.
Second, the failure to identify signatures of positive selection in the TRIM19 (PML) gene suggests that its encoded protein does not have antiviral activity, or that the protein acts as an intermediary, lacking a physical protein-protein interaction with the pathogen. TRIM19 (PML) has been implicated in many functions, for example, in apoptosis and cell proliferation [9]. In addition, TRIM19 (PML) expression may act as an effector of the antiviral state induced by type I interferons [9]. Overexpression of TRIM19 (PML) is reported to confer resistance to infection by vesicular stomatitis virus and influenza A virus. Rabies, Lassa virus and lymphocytic choriomeningitis virus replicate to higher levels in PML-negative cells, whereas overexpression of the protein has no significant effect. Various roles have been proposed for TRIM19 (PML) in retroviral replication $[8,25]$, although these findings remain controversial [26]. Many other viruses, including herpes simplex type 1 disturb the nuclear bodies that contain, among other proteins, TRIM19 (PML). However, it is unclear whether these effects are a consequence of the viral infection or a sign of its participation in antiviral defense. Thus, the effect of TRIM19 (PML) might be indirect. Failure to identify a signature of positive selection militates against a direct role of this protein in antiviral defense, because it would be expected that a prolonged contact with multiple pathogens over long evolutionary time periods would have resulted in signatures of positive selection indicative of a genetic conflict.

Finally, the absence of a signature of positive Darwinian selection in Cyclophilin A provides a complement to the understanding of the role of this protein in retroviral pathogenesis. Cyclophilin A interacts directly with the HIV-1 capsid, an interaction that may protect HIV-1 from antiviral restriction activity [27]. Although required by

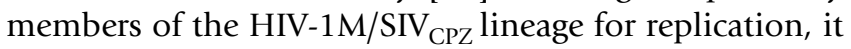
is not needed by other primate immunodeficiency viruses [11]. Owl monkeys exhibit post-entry restriction of HIV-1 mediated by a TRIM5-Cyclophilin A fusion protein generated by retroposition [28]. Evolutionary analysis of PPIA indicates that Cyclophilin A has been preserved by strong purifying selection, leaving its protein sequence virtually unchanged. This is consistent with the interaction of Cyclophilin A and the viral capsid being limited to the HIV-1M/SIVcpz lineage.

Together, the results presented here further support that an evolutionary genomics approach may be very useful for systematically assessing functional roles of primate host proteins potentially relevant in viral pathogenesis [29]. Candidates for this approach may include other members of the TRIM or APOBEC families [30,31] as well as proteins involved in pathogen recognition and life cycle. Signatures of positive selection, but also the absence of signs of a genetic conflict, constitute relevant informa- 
tion for understanding the nature of virus-host protein interactions.

\section{Competing interests}

The author(s) declare that they have no competing interests.

\section{Authors' contributions}

MO carried out the molecular genetic studies, performed sequence and phylogenetic analysis and contributed to drafting of the manuscript. GB and RM carried out molecular genetic studies. HK conceived the study, performed the evolutionary genomic analyses and drafted the manuscript. AT conceived the study, supervised the molecular genetic analysis, assured funding, and drafted the manuscript.

\section{Additional material}

\section{Additional file 1}

GenBank accession numbers.

Click here for file

[http://www.biomedcentral.com/content/supplementary/1742-

4690-3-11-S1.doc]

\section{Additional file 2}

Primers for amplification and sequence analysis.

Click here for file

[http://www.biomedcentral.com/content/supplementary/1742-

4690-3-11-S2.doc]

\section{Additional file 3}

Positive selected sites by Bayes Empirical Bayes Inference with probabilities $P>0.95$.

Click here for file

[http://www.biomedcentral.com/content/supplementary/17424690-3-11-S3.doc]

\section{Acknowledgements}

Supported by Swiss National Science Foundation grant no. 3 1 0000 - I 100 I $2 /$ I (to A.T.) and 3100A0-104I8I (to H.K.), research awards of the Cloëtta and Leenaards Foundations (to A.T.), and a grant for interdisciplinary research from the Faculty of Biology and Medicine of the University of Lausanne (to A.T. and H.K.).

\section{References}

I. Yang Z: The power of phylogenetic comparison in revealing protein function. Proc Natl Acad Sci U S A 2005, 102:3 I79-3।80.

2. Stremlau M, Owens CM, Perron MJ, Kiessling M, Autissier P, Sodroski $\mathrm{J}$ : The cytoplasmic body component TRIM5alpha restricts HIV-I infection in Old World monkeys. Nature 2004, 427:848-853.

3. Sawyer SL, Wu LI, Emerman M, Malik HS: Positive selection of primate TRIM5\{alpha\} identifies a critical species-specific retroviral restriction domain. Proc Natl Acad Sci U S A 2005, 102:2832-2837.

4. Sheehy AM, Gaddis NC, Choi JD, Malim MH: Isolation of a human gene that inhibits HIV-I infection and is suppressed by the viral Vif protein. Nature 2002, 4 I 8:646-650.
5. Sawyer SL, Emerman M, Malik HS: Ancient Adaptive Evolution of the Primate Antiviral DNA-Editing Enzyme APOBEC3G. PLoS Biol 2004, 2:E275.

6. Zhang J, Webb DM: Rapid evolution of primate antiviral enzyme APOBEC3G. Hum Mol Genet 2004, 13: I785- I79|.

7. Goodman M: The genomic record of Humankind's evolutionary roots. Am J Hum Genet 1999, 64:31-39.

8. Turelli P, Doucas V, Craig E, Mangeat B, Klages N, Evans R, Kalpana G, Trono D: Cytoplasmic recruitment of INII and PML on incoming HIV preintegration complexes: interference with early steps of viral replication. Mol Cell 200I, 7:1245-1254.

9. Nisole S, Stoye JP, Saib A: TRIM family proteins: retroviral restriction and antiviral defence. Nat Rev Microbiol 2005, 3:799-808.

10. Franke EK, Luban J: Inhibition of HIV-I replication by cyclosporine $A$ or related compounds correlates with the ability to disrupt the Gag-cyclophilin A interaction. Virology 1996, 222:279-282.

II. Braaten D, Franke EK, Luban J: Cyclophilin A is required for the replication of group $M$ human immunodeficiency virus type I (HIV-I) and simian immunodeficiency virus SIV(CPZ)GAB but not group $O$ HIV-I or other primate immunodeficiency viruses. J Virol 1996, 70:4220-4227.

12. Yang Z: PAML: a program package for phylogenetic analysis by maximum likelihood. Comput Appl Biosci 1997, 13:555-556.

13. Li WH: Molecular evolution Sunderland MA, Sinauer Associates; 1997.

14. Yang Z, Bielawski JP: Statistical methods for detecting molecular adaptation. Trends Ecol Evo 2000, I 5:496-503.

15. Yang Z, Nielsen R, Goldman N, Pedersen AM: Codon-substitution models for heterogeneous selection pressure at amino acid sites. Genetics 2000, 155:43I-449.

16. Yang Z, Wong WS, Nielsen R: Bayes empirical bayes inference of amino acid sites under positive selection. Mol Biol Evol 2005, 22:1107-1118.

17. Yang Z: Likelihood ratio tests for detecting positive selection and application to primate lysozyme evolution. Mol Biol Evol 1998, 15:568-573.

18. Song B, Gold B, O'Huigin C, Javanbakht H, Li X, Stremlau M, Winkler C, Dean M, Sodroski J: The B30.2(SPRY) domain of the retroviral restriction factor TRIM5alpha exhibits lineage-specific length and sequence variation in primates. J Virol 2005, 79:6|||-6|2|.

19. Stremlau M, Perron M, Welikala S, Sodroski J: Species-Specific Variation in the B30.2(SPRY) Domain of TRIM5\{alpha\} Determines the Potency of Human Immunodeficiency Virus Restriction. J Virol 2005, 79:3139-3।45.

20. Yap MW, Nisole S, Stoye JP: A Single Amino Acid Change in the SPRY Domain of Human Trim5alpha Leads to HIV-I Restriction. Curr Biol 2005, 15:73-78.

21. Conticello SG, Harris RS, Neuberger MS: The Vif protein of HIV triggers degradation of the human antiretroviral DNA deaminase APOBEC3G. Curr Biol 2003, 13:2009-20I3.

22. Gaddis NC, Sheehy AM, Ahmad KM, Swanson CM, Bishop KN, Beer BE, Marx PA, Gao F, Bibollet-Ruche F, Hahn BH, Malim MH: Further investigation of simian immunodeficiency virus Vif function in human cells. J Virol 2004, 78: I 204I-I 2046.

23. Schrofelbauer $B$, Chen $D$, Landau NR: $\mathbf{A}$ single amino acid of APOBEC3G controls its species-specific interaction with virion infectivity factor (Vif). Proc Natl Acad Sci U S A 2004, I01:3927-3932.

24. Mangeat $B$, Turelli $P$, Liao $S$, Trono $D$ : A single amino acid determinant governs the species-specific sensitivity of APOBEC3G to Vif action. J Biol Chem 2004, 279: I 448I-I 4483.

25. Regad T, Saib A, Lallemand-Breitenbach V, Pandolfi PP, de TH, ChelbiAlix MK: PML mediates the interferon-induced antiviral state against a complex retrovirus via its association with the viral transactivator. EMBO J 200I, 20:3495-3505.

26. Berthoux L, Towers GJ, Gurer C, Salomoni P, Pandolfi PP, Luban J: As(2)O(3) enhances retroviral reverse transcription and counteracts RefI antiviral activity. J Virol 2003, 77:3167-3|80.

27. Franke EK, Yuan HE, Luban J: Specific incorporation of cyclophilin A into HIV-I virions. Nature 1994, 372:359-362.

28. Sayah DM, Sokolskaja E, Berthoux L, Luban J: Cyclophilin A retrotransposition into TRIM5 explains owl monkey resistance to HIV-I. Nature 2004, 430:569-573. 
29. Telenti A: Adaptation, co-evolution, and human susceptibility to HIV-I infection. Infect Genet Evol 2005, 5:327-334.

30. Reymond A, Meroni G, Fantozzi A, Merla G, Cairo S, Luzi L, Riganelli D, Zanaria E, Messali S, Cainarca S, Guffanti A, Minucci S, Pelicci PG, Ballabio A: The tripartite motif family identifies cell compartments. EMBO J 200I, 20:2I40-2I5I.

31. Bogerd HP, Wiegand HL, Doehle BP, Lueders KK, Cullen BR: APOBEC $3 A$ and APOBEC $3 B$ are potent inhibitors of LTRretrotransposon function in human cells. Nucleic Acids Res 2006, 34:89-95.

Publish with Bio Med Central and every scientist can read your work free of charge

"BioMed Central will be the most significant development for disseminating the results of biomedical research in our lifetime. " Sir Paul Nurse, Cancer Research UK

Your research papers will be:

- available free of charge to the entire biomedical community

- peer reviewed and published immediately upon acceptance

- cited in PubMed and archived on PubMed Central

- yours - you keep the copyright

Submit your manuscript here:

http://www.biomedcentral.com/info/publishing_adv.asp 